Article

\title{
Exploring Farmers' Perceptions of Agricultural Technologies: A Case Study from Tanzania
}

\author{
Srijna Jha ${ }^{1,2, *}$, Harald Kaechele ${ }^{1,3}$, Marcos Lana ${ }^{1,4}\left(\mathbb{D}\right.$, T.S Amjath-Babu ${ }^{1,5}$ (D) and Stefan Sieber ${ }^{1,2}$ \\ 1 Sustainable Land Use in Developing Countries (SusLAND), Leibniz Centre for Agricultural Landscape \\ Research (ZALF), Eberswalder Straße 84, 15374 Müncheberg, Germany; harald.kaechele@zalf.de (H.K.); \\ marcos.lana@slu.se (M.L.); amjath.babu@zalf.de (T.S.A.-B.); stefan.sieber@zalf.de (S.S.) \\ 2 Department of Agricultural Economics, Faculty of Life Sciences Thaer-Institute, Humboldt-Universität zu \\ Berlin, Unter den Linden 6, 10099 Berlin, Germany \\ 3 Department of Environmental Economics, Eberswalde University for Sustainable Development (HNEE), \\ Schickler Straße 5, 16225 Eberswalde, Germany \\ 4 Department of Crop Production Ecology, Swedish University of Agricultural Sciences, Box 7044, \\ 76007 Uppsala, Sweden \\ 5 CIMMYT, Dhaka, Bangladesh \\ * Correspondence: srijna.jha@zalf.de; Tel.: +49-1636-960-469
}

Received: 30 December 2019; Accepted: 28 January 2020; Published: 30 January 2020

\begin{abstract}
The low agricultural productivity of key crops and food insecurity continue to be key issues in Sub-Saharan Africa (SSA) and Tanzania. The growing population, depleting resources, and changing climate further amplify these issues. Globally, many agricultural technologies (AgTs) are available as pathways for improved agricultural productivity and food security, however, they have had relatively little success in SSA and Tanzania. This is because the uptake of AgTs is a complex process, which is highly localized, involving multiple actors, stages, and spatial and time dimensions. Smallholder farmers often experience issues of sustainability, constraints for adoption, and scaling-up throughout the uptake process of AgTs, all of which vary by region. This indicates a need for a systematic and simultaneous understanding of sustainability, constraints for adoption, and scaling-up of AgTs to better guide agricultural strategy and policy interventions in SSA and Tanzania. Moreover, in order to understand the local settings better, a consideration of the perceptions of the farmers themselves, who are the primary actors in the uptake process of AgTs, is key. Acknowledging this, the study takes on a case study approach, using the scaling-up assessment (ScalA) method and three focus group discussions with a total of 44 smallholder farmers to systematically and simultaneously assess the sustainability, constraints for adoption, and scaling-up of three AgTs (use of fertilizers, improved seeds, and small-scale irrigation) in Tanzania. The study finds that the farmers perceive all three AgTs to be sustainable for the study region. Adoption rates are perceived to be medium for use of fertilizers, high for improved seeds, and low for small-scale irrigation. The most significant constraints for adoption experienced by the farmers are lack of technical physical inputs, marketing facilities, and know-how. Scaling-up is perceived to be well fulfilled for use of fertilizers and improved seeds, but only partially fulfilled for small-scale irrigation, which is the most limited of the three AgTs. The most significant constraints for scaling-up experienced by farmers are a lack of confidence in the added value of the AgTs beyond project activities, marketing facilities, and technical physical inputs. The overall success potential is high for the use of fertilizers and improved seeds, and the average for small-scale irrigation. The farmers' perceptions partially indicate why the bundle of AgTs is lacking in the study region and provide a basis for discussing targeted agricultural and policy interventions in Tanzania.
\end{abstract}

Keywords: sustainability; adoption; scaling-up; agricultural technologies; farmer perceptions; agricultural productivity; food security; Tanzania 


\section{Introduction}

The prevalence of food insecurity and poverty continue to be major concerns in Sub-Saharan Africa (SSA). Stagnating and low yields of key crops, increasing population, and changing climatic conditions further complicate the issues of food insecurity [1]. Agriculture, as the primary driver of the rural economy and livelihood in SSA, provides a pathway to long-term food security, poverty eradication, and rural development [2]. However, since the early 1960s the yield of key crops in SSA remained significantly below (less than $2 \mathrm{mt} / \mathrm{ha}$ in case of Maize) what can be attained by following good agronomic practices [2].

As with most SSA countries, Tanzania is also an agrarian economy that depends heavily on its smallholder farmers, who make up approximately $80 \%$ of the total agricultural production $[3,4]$. Similar to the larger context of SSA, issue of food insecurity is a serious concern in Tanzania. While the total cultivated land under agriculture in Tanzania expanded, the yields of key crops remained low and stagnant [3,4]. Since 2011, maize production has averaged approximately 1.3 metric tons per hectare, despite the quite favorable conditions for growing maize in Tanzania [5]. This is relatively low compared to the average maize production of $1.6 \mathrm{mt} / \mathrm{ha}$ in Kenya [6] and Ghana [7], $4.3 \mathrm{mt} / \mathrm{ha}$ in Vietnam [8], and $5.7 \mathrm{mt} / \mathrm{ha}$ in China [9]. Similarly, for rice, the average yield is approximately 2.0 $\mathrm{mt} / \mathrm{ha}$ in Tanzania [5] which is half compared to the average rice production of $4.0 \mathrm{mt} / \mathrm{ha}$ in Kenya [6] and less than one third compared to that of China (6.7 mt/ha) [9]. The Tanzanian national agendas and development goals often include optimization of agricultural productivity as a viable option for ensuring food security. However, in the last two decades no upward trend in crop yields was recorded (although variation exists due to changing rainfall patterns) [10]. To ensure better agricultural productivity and food security in Tanzania, a significant increase in crop yields is needed [2].

Agricultural technologies (AgTs), such as the use of fertilizers, improved seeds, and small-scale irrigation dramatically increased the yields of key crops and provided a viable pathway for food security in many Latin American and Asian countries [11]. Globally, there is ample evidence of AgTs that are useful for addressing issues of low agricultural productivity and food insecurity [12]. However, in SSA and Tanzania, the impact of AgTs on agricultural productivity and overall food security is limited. Authors most commonly state issues of sustainability $[2,13]$ often related to irrigation water and depletion soil nutrients (soil degradation), weaker market for seeds, fertilizers and agricultural outputs, leading to non-adoption [14] and failure to scale-up AgTs [15], as reasons for the stagnating productivity in SSA and Tanzania.

A transformation of the agricultural sector in rural areas for increased agricultural productivity and food security requires the adoption of AgTs that are sustainable [13]. A study by Otsuka and Muraoka [2], argues that the sustainability and relevance of AgTs vary depending on the region and country. AgTs that are perceived as sustainable and inclusive may work out quite differently when applied on a larger scale or under different ecological, geographical, or political conditions [16,17]. For example, the national and international programs in Tanzania and SSA, which in an effort to expedite the agricultural optimization process, chose to introduce seed varieties that were unsuitable (choosing varieties from Asia and Latin America) rather than identifying and developing locally viable varieties [18]. Furthermore, a study by Enyong, Debrah, and Bationo [19] in Western Africa concludes that the adoption of soil fertility enhancing AgTs (such as use of fertilizers) by farmers is influenced by how they perceive the contributions of an AgT towards sustainability. Therefore, before an AgT is introduced, promoted, and implemented, its sustainability for the local region must be investigated and include the perceptions of the farmers.

Nevertheless, effective adoption and scaling-up of sustainable AgTs has great potential to develop the agricultural sector in rural areas and ensure food security [20]. However, different AgTs face different constraints for adoption and scaling-up, which vary by region because adoption processes are 
highly localized [15]. Furthermore, several authors have shown that farmers' perceptions influence their adoption and scaling-up decisions [21-23]. A study by Sieber et al. [24] in Tanzania discusses the scaling-up of AgTs based on the initial resource requirements for adoption. Studies by Versteeg and collegaues [25] as well as Douthwaite and colleagues [26] suggest that when farmers are able to adopt the new AgT in their local context first, with the possibility to adapt it, the likelihood of successful and sustainable scaling-up of the AgT increases. The perceptions and views of the community are at the center of the uptake process of AgTs [27]. A study by Adesina and Baidu-Forson [28] discusses the limited role of farmers' preferences in adoption studies conducted by economists and argues that farmers' perceptions significantly affect their adoption decisions. Another study by Dessart and co-workers [29] suggests that understanding and including the role of factors related to farmer behavior and perceptions in adoption studies is crucial to enhance traditional economic analysis of the farmers' decision-making. Therefore, before an AgT is introduced, promoted, and implemented, its adoption, scaling-up, and associated constraints as perceived by the farmers must be investigated.

Several studies [2,13-15] explored the uptake process of AgTs. However, most studies were carried out from a policy, governance, empirical, or technological perspective. The emphasis is on the role of prices, farmer characteristics (such as income, risk-aversion, time preferences, education, etc.), and attributes of the technology itself as important predictors of success of AgTs [30,31], often focusing on either sustainability, adoption, or scaling-up. Relatively little work in Tanzania systematically and simultaneously examines all three aspects (sustainability, constraints for adoption, and scaling-up) of AgTs as perceived by the farmers themselves.

To address this research gap, the study presents an explorative investigation of the sustainability, adoption, and scaling-up of AgTs in Tanzania from the farmers' perspective. Here, sustainability of an AgT refers to the contribution of an AgT to the economic, ecological, and social capacities of the farmers [32]. Adoption refers to the initial and continued use of an AgT by the farmers [23]. Scaling-up refers to the likelihood of an AgT to be adopted by large numbers of farmers [24].

The objectives are as follows:

1. Evaluate the sustainability of AgTs as perceived by the farmers.

2. Identify and discuss the most significant constraints as perceived by the farmers for the adoption of AgTs.

3. Identify and discuss the most significant constraints as perceived by the farmers for the scaling-up of AgTs.

4. Evaluate the overall (integrated) success potential of the AgTs.

The study achieves its objectives by using the scaling-up assessment (ScalA) method [24] and focus group discussions (FDGs) with farmers. The contributions of the study are threefold: First, the study provides a comprehensive and integrated systematic analysis of the factors of sustainability, adoption, and scaling-up of AgTs in Tanzania. Second, the study adds to the relatively limited literature on farmers' perceptions of AgTs in Tanzania and associated constraints of adoption and scaling-up, thus providing a unique look into the experiences of the farmers. Third, the study provides, as examples, the sustainability, adoption, and a scaling-up assessment of three key AgTs, and thus adds case study-specific literature for these three AgTs. The assessment of sustainability, adoption, and scaling-up potential within the ScalA framework is a translation of qualitative information, which requires thoughtful interpretation. The analytical value lies in the comparability of different AgTs and not as quantitative measures of the uptake of an AgT.

\section{Materials and Methods}

\subsection{Study Region}

The regions of Morogoro and Dodoma in Tanzania were the selected case study sites as defined by the "Tran-SEC_-Innovating Strategies to safeguard Food Security using Technology and Knowledge 
Transfer: A people-centered approach" project [33]. Droughts are the most important aspect of climate variability in Tanzania, often causing food shortages. Shorter dry spells of a week or two during critical periods of the growing season can reduce crop yields significantly [34]. Three villages, Fulwe, Mlali, and Msowero from the regions of Morogoro and Dodoma were selected as a representative example of the agricultural community in Tanzania. This was done to include the two contrasting food systems found in the two regions of Morogoro and Dodoma. Morogoro is a semi-humid region with 350-500 mm yearly rainfall, highlands, lowlands, and dry alluvial valleys. The main crops are maize, rice, legumes and sorghum [35]. In years with high rainfall, Morogoro experiences flooding in the southern part of the region [36]. In contrast, Dodoma is a semi-arid region of mostly flat plains and small hills. The main crops are sorghum and millet. In years with low or uncertain rainfall the region experiences both extended and seasonal dry spells [35]. In Fulwe, Mlali, and Msowero drought, deforestation, maize yield decline, and limited profitability from agriculture are initially stated as issues of agricultural productivity. In Msowero the stated issues are the most severe.

\subsection{Selected AgTs}

As a first step we selected AgTs that were already introduced and known to the farmers. Then out of the initial set of AgTs, we selected those which are viewed as crucial for crop production, with the highest relevance for improving food security [11] in the study region and with documented proof of capacity to increase crop yields [2]; namely, use of fertilizer, improved seeds, and small-scale irrigation. In this context, "use of fertilizer" refers to the shift to inorganic and chemical-based fertilizers [37]. In the study region, diammonium phosphate (DAP) and urea are the most commonly used fertilizers for both irrigated and non-irrigated production systems, primarily for maize, followed by rice, beans, and vegetables [38]."Improved cultivars" refer to the development of improved seeds through the High Yielding Variety Seed Program (H.V.P.). In the study region, the availability of adequate seed varieties would address major challenges such as tolerance to drought, cold weather, major insect pests, and diseases facing the rice and maize sector in the region [39]. "Small-scale irrigation" refers to irrigation methods [11] such as use a bucket or watering cans, surface or flood irrigation, furrow, and sometimes drip irrigation [40].

\subsection{Assessment Method}

The literature on each of the dimensions of sustainability [41,42], adoption [43,44], and scaling-up [45,46] of AgTs is extensive. However, an integrated common framework that includes all three dimensions (sustainability, adoption, and scaling-up) of AgTs is lacking. Therefore, in choosing a framework for this study, we selected the scaling-up assessment (ScalA) method by Sieber et al. [24], which allows for an integrated systematic assessment of all three aspects (sustainability, adoption, and scaling-up). Moreover, the ScalA framework is feasible to implement with the farmers and also considers the highly context-specific needs and conditions of the study. It is an Excel-based tool developed by GIZ (German Society for International Cooperation) and ZALF (Leibniz Centre for Agricultural Landscape Research) [47], which facilitates a rapid assessment of an AgT with low costs and time investments [24]. The tool uses a series of closed questions and asks farmers to provide inputs. It consists of a multi-step analysis with four main parts-sustainability, adoption, scaling-up, and integrated (overall) assessments. In order to conduct a complete assessment of an AgT, the four parts of the ScalA tool are sequentially followed.

The study carries out the farmer focus group discussions within the ScalA framework to assess the perception of the farmers regarding the sustainability, adoption, and scaling-up of the selected AgTs. It investigates the perceptions of the farmers and not the "actual" sustainability, adoption, and scaling-up of the selected AgTs. It is assumed that the farmers' perceptions of sustainability, adoption, and scaling-up potential differ from AgT to AgT, and the same AgT can have different outcomes in different settings and under different circumstances. Sustainability, adoption, and scaling-up of an AgT are therefore influenced by characteristics of the AgT as well as by external conditions and strategies used for its 
implementation. The sustainability, adoption, and the potential for scaling-up an AgT, as perceived by the farmers can, therefore, be derived from the assessment of the set of factors of the ScalA tool [24]. Sustainability, adoption, and scaling-up factors are those factors that influence the dissemination of AgTs either in a negative or positive way and thus determine the potential of an AgT. The factors identified, defined, and included in the ScalA tool are derived from various case studies from Asia and Africa by creators of the ScalA tool, comprising managers, scientists, development workers, farmers, extension officers, and decision makers across various disciplines, regions, and institutes [24].

The ScalA algorithm defines sustainability, adoption, scaling-up, and overall success potential of an AgT as follows.

1. Sustainability: Scoring of 17 economic, ecological, and social sustainability factors (Appendix A).

2. Adoption: Scoring of 11 adoption factors (Appendix B).

3. Scaling-up: Scoring of 59 scaling-up factors (Appendix C).

4. Overall success potential: Integrated analysis of the scores from sustainability, adoption, and scaling-up [24].

The farmers assign scores to each of the 17 sustainability factors. Here the sustainability factors represent the social, economic, and ecological contributions of an AgT. An AgT may be perceived to contribute to one, two, or all (social, economic, ecological) dimensions of sustainability. The sustainability scores indicate whether the sustainability factor is fulfilled (1) or not (0). ScalA assumes that an AgT is sustainable if it enhances at least one of the three sustainability dimensions without deteriorating any other. The ScalA analysis starts with an assessment of the AgT's sustainability as a precondition for further adoption and scaling-up assessments. In order to assess whether an AgT is considered as sustainable, ScalA considers the number of dimensions of sustainability factors fulfilled. The likelihood that a farmer adopts an AgT depends on at least one or more of the three dimensions of sustainability being well fulfilled. This is indicated by the farmers' perception of the degree to which an AgT may positively contribute towards the social, economic, and ecological sustainability of their agricultural systems and households. The final sustainability results, representing the aggregation of all sustainability factors, show if an AgT is perceived as sustainable or not and are presented as such.

The farmers assign scores to each of the 11 adoption factors. Here the adoption factors represent the initial resources required (social, economic, ecological, institutional) for the initial adoption of an AgT. An AgT is perceived to require low, medium, or high resource inputs. The adoption scores indicate how high the initial resource requirements are on a scale of 0 to 3 where 0 indicates that the adoption factor is not relevant, 1 indicates that the resource requirement is low, 2 indicates medium resource requirement, and 3 indicates that the resource requirement is high. Adoption factors with the highest farmer scores and occurring with the most frequency are then traced to identify the most significant constraints for adoption, as experienced by the farmers. ScalA assumes that the higher the adoption resource requirements, the more difficult the farmers find the adoption pathway of an AgT and vice versa. The final adoption results, representing the aggregation of all adoption factors, are presented as low, medium, or high indicating a relatively difficult, average, and easy adoption pathway of an AgT, respectively.

The farmers assign scores to each of the 59 scaling-up factors. Here the scaling-up factors represent the resources required (social, economic, ecological, institutional) for continued adoption of an AgT by a larger number of farmers. The scaling-up factors of an AgT is perceived to be partially fulfilled, medium fulfilled, or well fulfilled. The scaling-up scores indicate how an AgT is perceived to meet the scaling-up factors on a scale of 0 to 6. The ScalA tool links the adoption and scaling-up factors [24]. Here, 0 indicates that the scaling-up factor is not relevant, 1-2 indicate that the scaling-up factor is high (well) fulfilled, 3-4 indicate that the scaling-up factors are medium (average) fulfilled, and 5-6 indicate that the scaling-up factors are low (partially) fulfilled. The scaling-up factors with the highest scaling-up scores and occurring with the most frequency (meaning they were the least fulfilled and most significant) are then traced to identify the most significant constraints for scaling-up, as 
perceived by the farmers. ScalA assumes that the higher the scaling-up resource requirements, the more difficult the farmers find the scaling-up pathway of an AgT and vice versa. The final scaling-up results, representing the aggregation of all scaling-up factors, are presented as low, medium, and high fulfilled indicating a relatively difficult, average, and easy scaling-up pathway of an AgT, respectively.

The integrated result indicating the overall success potential of an AgT takes into account the scores of all three assessments—sustainability, adoption, and scaling-up. As a first step, the ScalA method first evaluates if an AgT is sustainable or not. Only if the AgT is sustainable, does ScalA prompt for the assessment of the adoption and scaling-up factors. The farmer scores for the adoption factor are then linked with the farmer scores of the scaling-up factors to calculate the deviation of the current (actual, farmer) scenario from an optimum (ideal) one. This indicates how much the present conditions, as perceived by the farmers, differ from perfect or ideal conditions [24] for the implementation of AgTs in the region. The final overall success potential results, representing the aggregation of all sustainability, adoption, and scaling-up factors are presented as low, medium, and high, indicating relatively difficult, average, and easy pathways for the overall uptake of an AgT, respectively.

ScalA assumes that the likelihood of successful uptake of an AgT (overall success potential) is high when the sustainability factors are fulfilled and the adoption and scaling-up constraints are low, and vice versa. The sustainability, adoption, scaling-up, and overall success potential results are a measure of the farmers' perceptions of the degree to which factors for sustainability, resource requirements for adoption, and scaling-up are met or constrained.

\subsection{Research Design}

With the aim of understanding the perceptions of farmers in regard to the sustainability, adoption, and scaling-up of the three selected AgTs (use of fertilizers, improved seeds, and small-scale irrigation), the study utilizes the following research design (Figure 1).
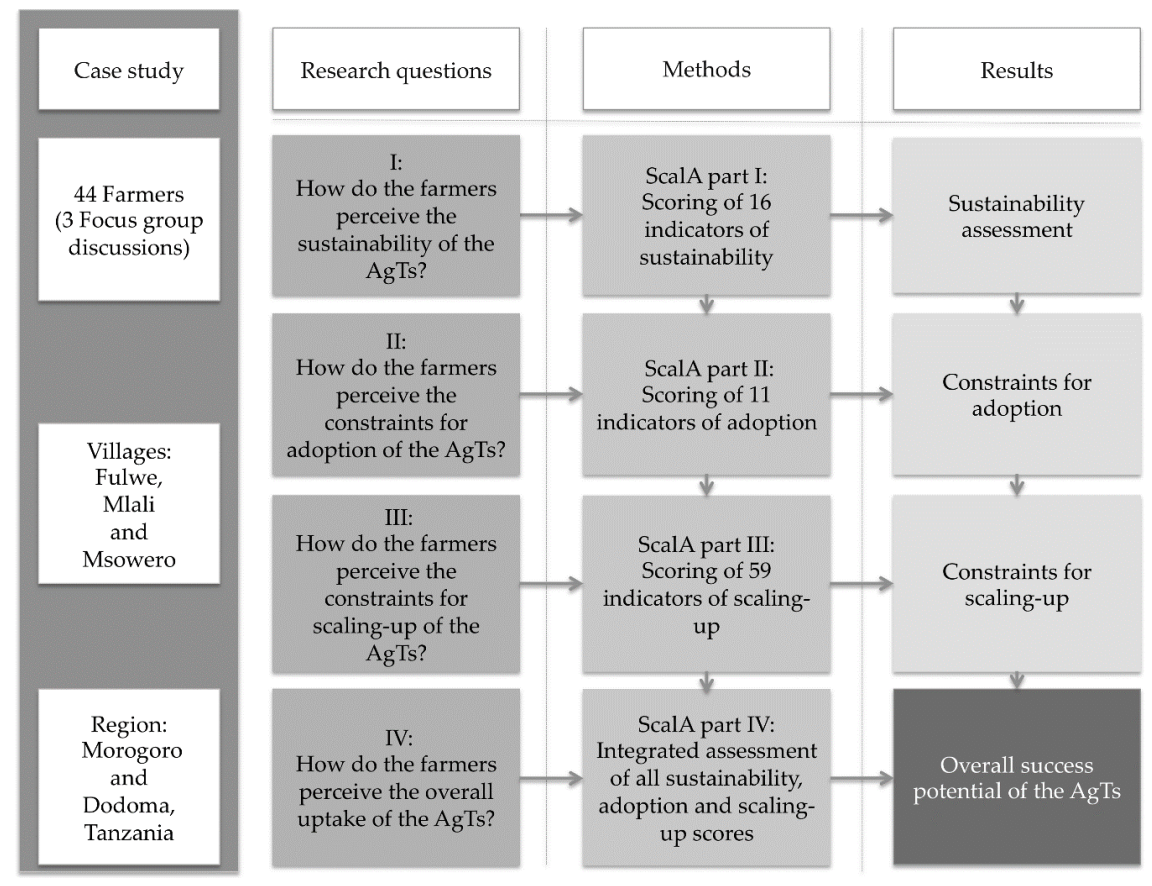

Figure 1. Research design.

The selected AgTs were evaluated with a randomly selected pool of 44 smallholder farmers from the three villages of Fulwe, Mlali, and Msowero. Three focus group discussions with 14-15 farmers per session were carried out. Table 1 gives an overview of the characteristics of the farmers included in the study. 
Table 1. Overview of the characteristics of the farmers included in the study.

\begin{tabular}{|c|c|}
\hline & Case Study \\
\hline Total number of farmers & 44 \\
\hline Number of female farmers & 14 \\
\hline Number of male farmers & 30 \\
\hline Age range & $22-74$ years \\
\hline Average age & 41 years \\
\hline Main crops & $\begin{array}{l}\text { maize, onions, one farmer reported cultivating } \\
\text { tomatoes and watermelon, another farmer reported } \\
\text { cultivating sorghum, and one reported paddy }\end{array}$ \\
\hline Average household size & 4 \\
\hline Land holdings (range) & $0.5-7$ acres \\
\hline Average land holdings & 2.29 acres \\
\hline Rainwater availability & $2-3$ months \\
\hline Access to fertilizers & $21 \%$ \\
\hline Access to groundwater for irrigation & $37 \%$ \\
\hline Permanent access to water for irrigation & $8 \%$ \\
\hline Migration among village population (past 10 years) & $30 \%$ \\
\hline Migration among respondents (past 10 years) & $37 \%$ \\
\hline Perception of infrastructure & poor-good \\
\hline Access to a tractor & $83 \%$ \\
\hline Access to associations & $44 \%$ \\
\hline Access to extension services & $56 \%$ \\
\hline
\end{tabular}

\section{Results and Discussion}

\subsection{Farmers' Perceptions of Sustainability}

The results indicate that overall the farmers find all three AgTs to contribute to one or more of the three social, economic, and ecological dimensions of sustainability and none is perceived to have a negative impact on the perceived sustainability of the agricultural systems in the study region. Each of the AgTs fulfills the minimum sustainability requirements and preconditions for subsequent adoption and scaling-up. All three AgTs are perceived to lead to improvements in income, food security, the competitiveness of small-scale farmers, and resource use efficiency. Figure 2 shows an overview of the 16 sustainability factors and the farmer scores for each AgT. The farmer scores are based on the average of findings (scores) from three focus group discussions and indicate the degree to which each of the AgTs contributes towards the various aspects of sustainability. The study found that not all AgTs are perceived to contribute to all sustainability factors equally; meaning that the farmers perceive each AgT's contributions towards sustainability as varying and sometimes unique. For example, the use of fertilizers is perceived to be the only AgT that improves soil fertility, which may be of higher interest to farmers already facing a decline in soil fertility and issues of soil erosion. Therefore, this may serve as a starting point to better promote the uptake of use of fertilizers via targeted interventions. Similarly, improved seeds are perceived by farmers to uniquely contribute to improving biodiversity and decreasing dependency on inputs needed. This indicates that the uptake of improved seeds may be better targeted towards those farmers who have observed a loss of biodiversity and those who are highly dependent on markets and credit access for inputs such as seeds. Farmers perceive small-scale irrigation to uniquely contribute to better water quality, water supply, and division of labor; therefore, farmers concerned about water quality and supply and those who have limited labor available on the farm for irrigation may be more receptive to small-scale irrigation. 


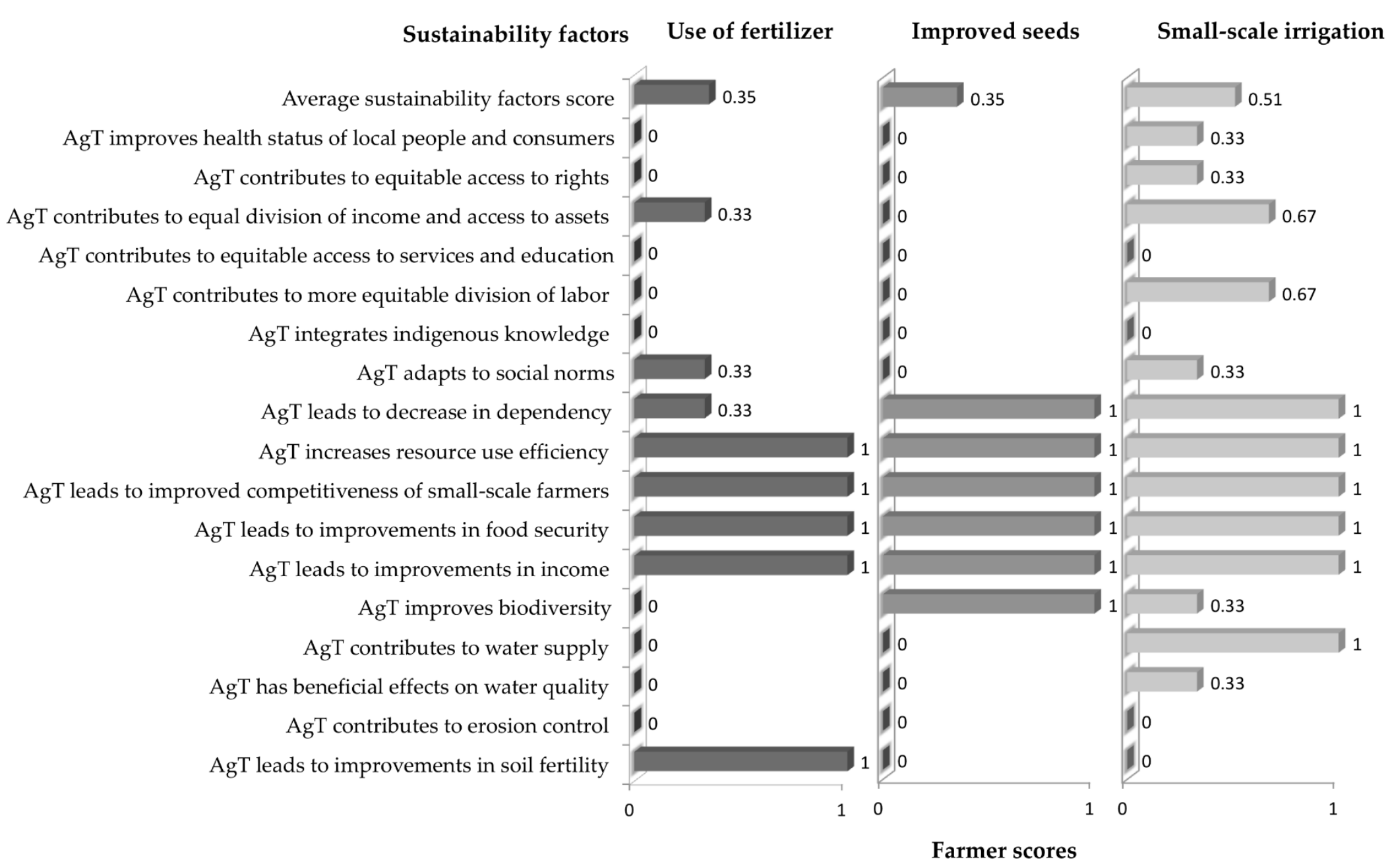

Figure 2. Overview of all 17 sustainability factors and the farmers' scores for the three agricultural technologies (AgTs). The first bar shows the average farmer score of all 17 sustainability factors. 
Overall, the farmers find that small-scale irrigation contributes to most factors of perceived sustainability, followed by improved seeds and use of fertilizers. We found that the literature on sustainability of use of fertilizers, improved seeds, and small-scale irrigation is inconclusive. Similar to the perceptions of the farmers, a study by Otsuka and Muraoka [2] concludes that AgTs, such as improved seeds from other parts of the world, like Asia and Latin America, are suitable and relevant for achieving an increase in the yield of key crops, such as rice in SSA. They present a case for the successful transfer of AgTs from Asia to SSA and find it as sustainable and relevant. In contrast to farmers' perceptions, Voortman [48] argues that the AgTs (use of fertilizers, improved seeds, and small-scale irrigation) failed in SSA because the promoted technologies were not appropriate under the environmental conditions of SSA. With the help of Sustainable Agriculture Tanzania (SAT) and National Networks of Farmers' Groups in Tanzania (MVIWATA), the African Centre for Biosafety (ACB) conducted a study to provide a thorough report on the current situation of important regions in Tanzania and the impact of these AgTs on small-scale farmers [4]. Similar to the perceptions of the farmers in our study region, a survey by the African Centre for Biosafety [4] of 60 farmers in Mvomero and Morogoro regions found that the farmers reacted positively to the AgTs (use of fertilizers, improved seeds, and small-scale irrigation) introduced via pilot programs.

In the study region, of the three AgTs, small-scale irrigation is perceived by the farmers as the most sustainable and relevant AgT for Tanzania. Other authors concluded similarly. De Fraiture and Giordano [49] argue that small-scale irrigation is the most feasible solution for the rapidly expanding agricultural sector in SSA and that it has the most potential for poverty alleviation and rural development. Domènech [50] emphasizes the role of small-scale irrigation as a sustainable solution to increase agricultural productivity and highlights its contributions towards farmers' diet, health, food security, and adaptive capacity in SSA. Harrison and Adee [51] argue that in Tanzania a positive outlook for a small-scale, community based and farmer driven irrigation exists. They found that small-scale irrigation enabled the development of horticulture and resulted in improvements in farmers' livelihoods in the Uluguru Mountains in Tanzania. On the other hand, Harrison and Adee [51] also found that small-scale irrigation in the Uluguru Mountains in Tanzania is seen by both representatives of the government and some donors, as the cause of both environmental degradation and water shortages downstream, in the nearby region of Morogoro, Tanzania. Similar to the farmers' perceptions, many authors found that AgTs, such as improved seeds and use of fertilizers, were sustainable and relevant for SSA and Tanzania, [1,2,4,52]. To ensure long-term sustainability and food security, these authors furthermore emphasize that AgTs may need to be improved and adapted to the local context and not simply transferred from one region to another.

The farmers perceive all three AgTs to fulfill the minimum sustainability requirements and are relevant for the study region. The results indicate that an integrated bundle of AgTs would contribute to a greater number of sustainability factors than individual AgTs applied one at a time. Similarly Otsuka and Muraoka [2] discuss the development and dissemination of integrated packages of new and useful AgTs and improved management practices.

\subsection{Farmers' Perceptions of Constraints for Adoption}

For the three AgTs, the farmers find all 11 adoption factors to be relevant. Of the 11, the farmers find technical and physical inputs, marketing facilities, and know-how skills as the most significant constraints for adoption of the selected AgTs in the study region. Similarly, The African Centre for Biosafety [4] report found the constraints in the adoption of AgTs in Tanzania to be physical and economic access to inputs (fertilizers and improved seeds), low levels of input application, crop management skills (know-how), poor market linkages, and infrastructure. Figure 3 shows an overview of the adoption factors and the farmer scores for each AgT. The farmer scores are based on the average findings (scores) from three focus group discussions and indicate how the farmers perceive the resource requirements for the initial adoption for each AgT. The assessment of the three AgTs using ScalA shows that overall the farmers perceive the use of fertilizer to be moderately constrained. Improved 
seeds are perceived to have fewer constraints. Small-scale irrigation is perceived as highly constrained. This indicates that the farmers anticipate a relatively easy adoption pathway for the use of fertilizers and improved seeds, whereas, they anticipate a relatively difficult adoption pathway for small-scale irrigation. The farmers find that use of fertilizers and improved seeds require high technical, organic, and physical inputs. They further recognize that use of fertilizer may be knowledge intensive and highly dependent on the market facilities available to the farmers. Similar to the use of fertilizers and improved seeds, the farmers acknowledge that small-scale irrigation requires a high input of technical and physical resources, may be knowledge intensive and dependent on marketing facilities. Furthermore, they anticipate that small-scale irrigation may require financial capital, additional land, labor, the support of social organizations and institutions, and better infrastructure. In the next section we further discuss the most significant constraints.

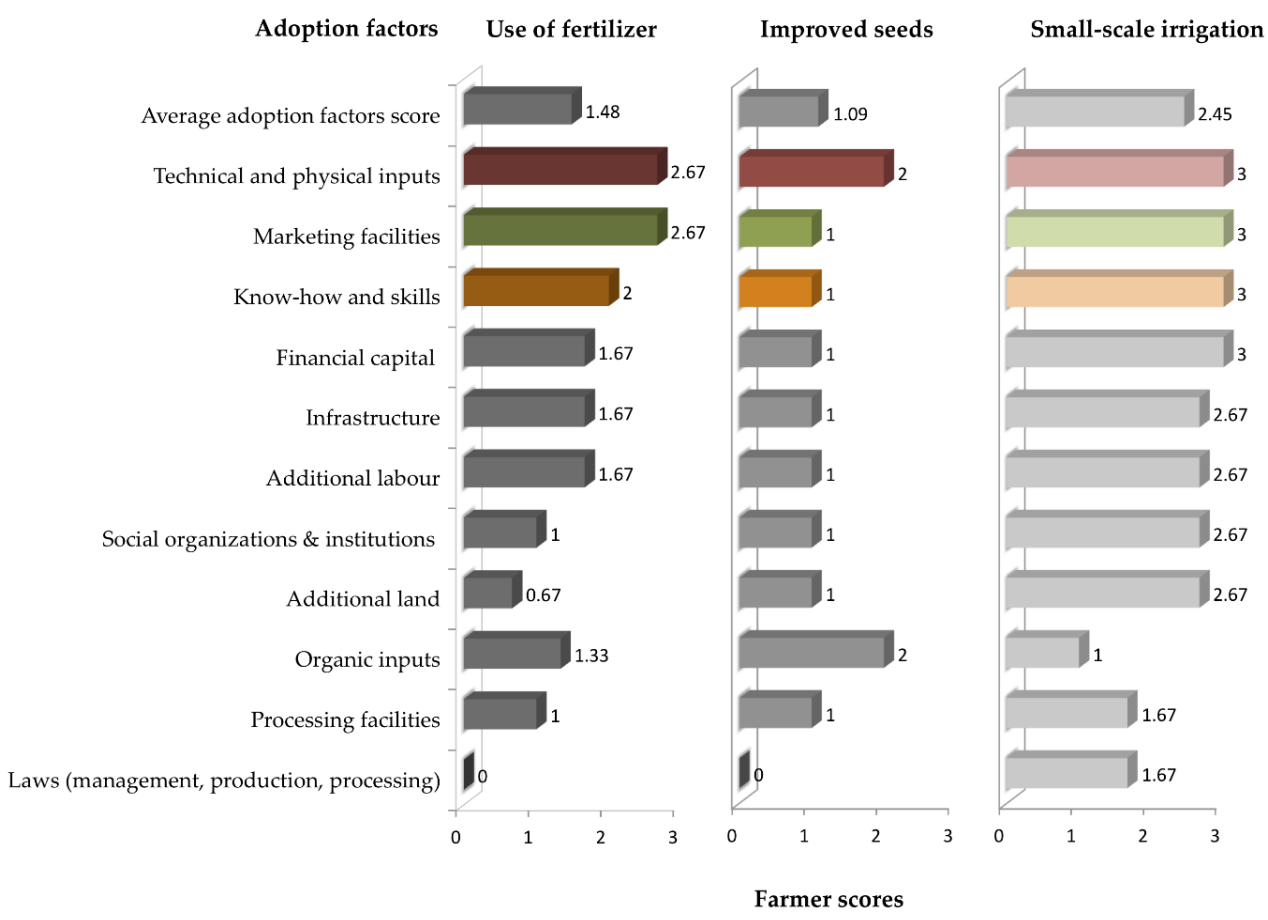

Figure 3. Overview of all 11 adoption factors and the farmers' scores for the three AgTs. The first bar shows the average farmer score of all 11 adoption factors. The adoption factors with the three highest scores indicating the highest resource requirements for the adoption process are traced and identified as the most significant constraints for the farmers.

\subsubsection{Technical and Physical Inputs}

We found that a lack of technical and physical inputs, such as machinery, shelter, construction material, animal draft power, vaccination, and synthetic fertilizer is perceived by farmers as a major constraint to the adoption of the AgTs in the region. The farmers noted that no support exists from other economic actors to promote the adoption of the AgTs. They also observed that sometimes, the existing agricultural system is not suited for the AgTs and requires high technical and physical inputs.

Similar to the experiences of the farmers in the study region, a lack of technical and physical input is often cited as a reason for the failure of AgTs in SSA by several empirical and policy studies [53]. For example, Sanchez [54] discusses the reasons for low fertilizer adoption in SSA and attribute a large part to the limited inputs and associated high fixed costs, including the high price of fertilizers. In the The African Centre for Biosafety [4] report, participating farmers from Tanzania also indicated that while they were able to apply some of the AgTs, they lacked the resources to apply others, in particular fertilizer and pesticides. In their study on factors influencing adoption, Mugisha and Diiro [55] also found that access to credit relaxes income constraints for farmers, which provides them with access 
to key inputs as well as the opportunity to hire labor. Other studies provide other reasons for the low adoption and application of AgTs, such as unavailability, credit constraints, and high transaction costs [2]. All of which relates back to the technical and physical inputs needed for adoption.

Similar to the farmers' perceptions, other studies also cite the lack of seeds (inputs) as a key constraint for the adoption of improved seeds [56]. The authors of The African Centre for Biosafety [4] report similar results. They further argue that once a seed enters circulation it should be considered part of the farmers' asset base to nurture and grow, with support from public sector institutions and expertise to maintain and improve on that variety, for local use and even commercially, if acceptable standards are met [4]. A policy that prevents farmers from freely adapting and using whatever seed (inputs) the farmers have at their disposal threatens the adoption process.

In line with the farmers' perceptions, other studies found that the potential of small-scale irrigation to contribute to the transformation of agriculture is increasingly stressed in SSA $[57,58]$ and Tanzania [59], but still is the most limited AgT of the three. In their study, Harrison and Mdee [51] argue that irrigation practice in Tanzania is embedded in long-standing social relationships, which people do not articulate as formal rules, but as their way of being 'together'. This mix of formal and informal ways constrains the access to technical and physical inputs (land, water, credit), resulting in limited adoption of small-scale irrigation in Tanzania.

\subsubsection{Marketing Facilities}

We found that the farmers observe a lack of marketing facilities as a major constraint for adoption. The farmers note that no stable market or marketing facilities to buy or sell inputs and products exists. When they do exist, they are not easily accessible [53]. The African Centre for Biosafety [4] report found that the farmers also indicated marketing facilities as one of their main constraints for the adoption of AgTs. Market access is a central aspect of AgT interventions since farmers will be able to access and afford costly inputs for AgTs only if they can increase their incomes from sales to pay for the inputs, and this is only possible with good marketing facilities. Suri [60] suggests that removing supply and infrastructure constraints for farmers, such as long travel time to seed and fertilizer distributors, would be a cost-effective policy to raise adoption rates. Recognizing this, in Tanzania and Mozambique, in an effort to reduce the transportation costs that make up the bulk of the cost of fertilizers, manufacturers and governments are working to upgrade and better link port facilities with inland locations [54]. It is also noted that in Tanzania, where market facilities are improving and agro-inputs are present, the adoption of AgTs is increasing [4,54].

\subsubsection{Know-How Skills}

We found that the farmers see a lack of know-how and skills to carry out the adoption of the AgTs as a major constraint. The farmers in the study region do not have access to knowledge to learn how to implement the AgTs successfully, nor do they have sufficient previous knowledge regarding the implementation of the three AgTs. They also observed limitations due to the complexity of the information available (not easy to understand) and that the technical and management staffs of implementing organizations are not well educated or trained. Other authors found similar results. The lack of agricultural information is often cited as a major constraint for the adoption of AgTs [61], and the diffusion of information relevant for the adoption of AgTs is increasingly studied [62] A report by The African Centre for Biosafety [4] on the impact of AgTs in Tanzania concludes that new AgTs are not automatically and necessarily negative; but in order for farmers to have meaningful choices they must receive a range of information that highlights both the pros and cons of different technologies. For example, the report [4] found that the farmers did express interest in learning more about seed production and said they were sure they could produce quality seed themselves if they could acquire the technical knowledge. The authors argue that introducing farmers to seed production in a systematic way, which includes production of their own varieties for local use as well as for expanded distribution within the agro-ecological zones for which the seed is adapted, is key. 


\subsection{Farmers' Perceptions of Constraints for Scaling-Up}

Of the 59 scaling-up factors, the farmers find 39 to be relevant. Of the 39 , the farmers find the lack of added value beyond implementation activities, lack of predictable and stable marketing facilities, and lack of technical physical inputs as the most significant constraints for scaling-up of the selected AgTs in the study region. The assessment of the three AgTs using ScalA shows that use of fertilizers and improved seeds well fulfill the scaling-up resource requirements, whereas, small-scale irrigation only partially fulfills the scaling-up resource requirements. Figure 4 shows an overview of the scaling-up factors and the farmers' scores for each AgT, based on the average of findings (scores) from three focus group discussions. When considered individually, the farmers find that in addition to overall constraints each AgT is further limited by other scaling-up factors. They find that the use of fertilizers is further limited by the economic risks faced by the farmers, the know-how needed, the impact of AgT on the land and water resources, and the limited contribution of an AgT to the farmer's autonomy. Improved seeds are perceived to be further limited by lack of mechanisms for international standardization, lack of contribution of AgTs towards farmer autonomy, lack of processing facilities, and lack of initial organic inputs. The farmers recognize small-scale irrigation to have the maximum number of constraints of the three AgTs. They indicated the lack of mechanisms for international standardization, lack of knowledge regarding $\mathrm{AgT}$, the associated economic risk, the negative impact of AgT on land and water resources, the affordability, suitability, and adaptability of the AgTs as other major constraints for scaling-up. In the next section, we further discuss the most significant constraints.

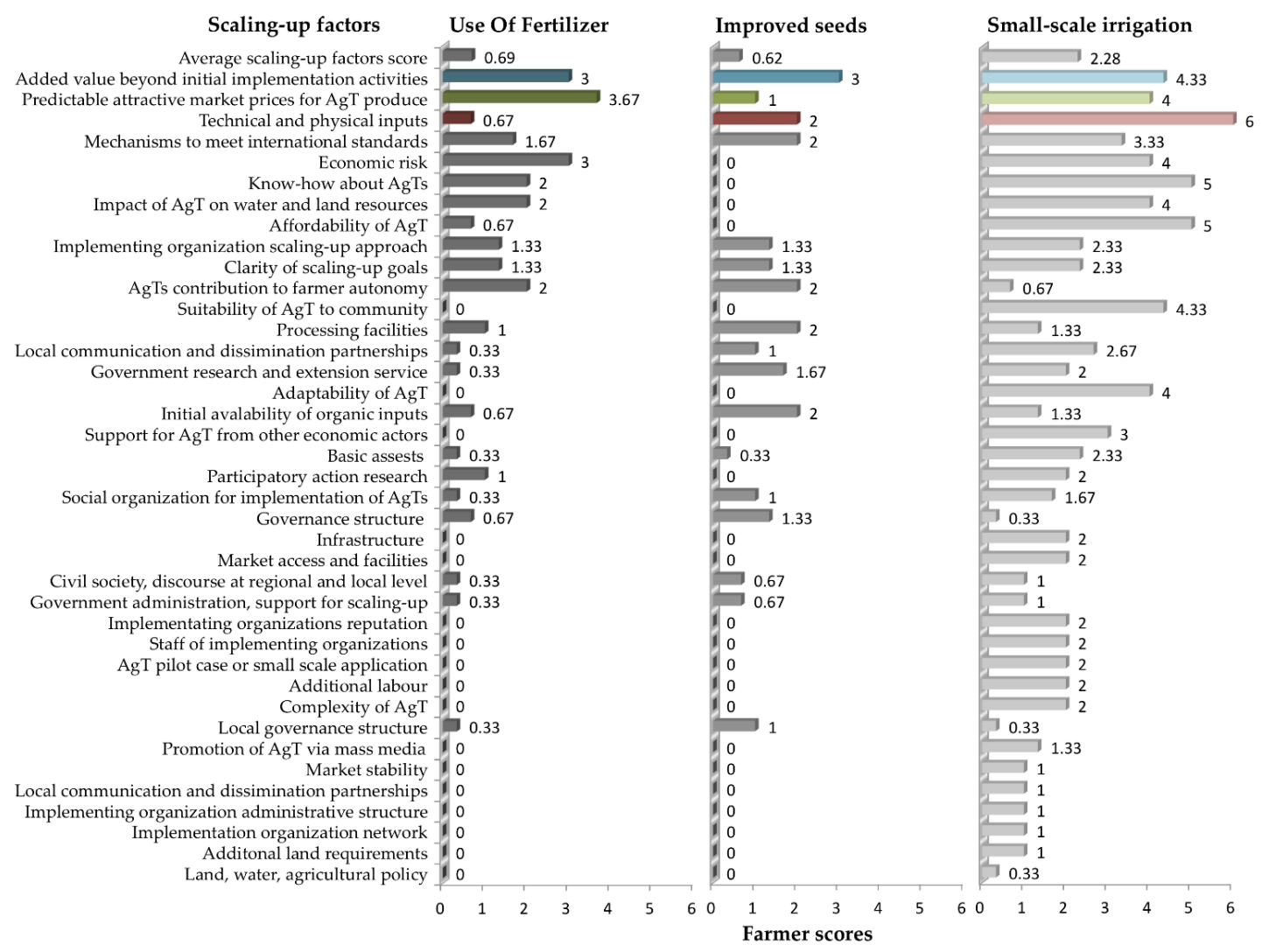

Figure 4. Overview of the scaling-up factors and the farmers' scores for the three AgTs. Out of the 59 scaling-up factors included in the scaling-up assessment, the figure shows only 39 scaling-up factors, which are relevant for the farmers. The first bar shows the average farmer score of the 39 scaling-up factors. The scaling-up factors with the highest scores indicate the highest scaling-up resource requirements, which are traced and identified as the most significant constraints for the farmers. 


\subsubsection{Added Value beyond Initial Implementation}

The study found that the limited perception of added value (benefits) of an AgT towards a farmer's livelihood, autonomy, and prestige beyond the project lifetime is a major constraint for scaling-up. A farmer is less likely to scale-up an AgT whose value he or she cannot see or imagine over time. The farmers find that implementing organizations should not only look at the short-term economic importance of AgTs, but also its long-term socio-economic importance to the local people (farmers) in the area. Similarly, Kahimba and colleagues [63] discuss the desire of a farmer to adopt and scale-up AgTs as being driven by perceptions of added value, which therefore should be amongst the most important scaling-up factors that the government and development partners should consider. Similar to the farmers' perceptions, a report [4] on the impact of the AgTs in Tanzania states that the longer-term benefits of the increased use of AgT inputs on biodiversity, soil life, water systems, and social equality is not clear in Tanzania, which hampers the uptake process of AgTs. The Alliance for a Green Revolution in Africa (AGRA) in Tanzania also recommends that these aspects of AgTs be monitored closely, together with farmers. Similarly, several other authors discuss the uptake process of an AgT over time, both short-term and long-term. Matsumoto, Yamano, and Sserunkuuma [61] conducted an experiment among farmers in Uganda, in which a group of farmers were provided free start-up packages consisting of improved seeds and fertilizers. The study found that these farmers had a higher likelihood of scaling-up AgTs than their counterparts, farmers who did not receive the free start-up packages. They concluded that, if a farmer is not aware of both the short-term and long-term benefits (added value) of an AgT, he or she may not adopt or scale-up the AgT. Hence the study proves that communication of the added value of an AgT is an important strategy to change farmer behavior. Another study [64] also found that demonstration plots, input suppliers, and extension workers were more effective sources of information regarding the use and added value (benefits) of AgTs, which led to a better uptake of AgTs.

\subsubsection{Marketing Facilities}

Similar to our adoption results, the farmers find a lack of stable and reasonable prices for agricultural produce in the study area to be a major constraint for scaling-up. Similarly, a study by Pingali, Bigot, and Binswanger [65] on mechanization in SSA concludes that population growth and market access are the main determinants of intensification. A study by Poulton et al. [66] compares agricultural intensification models in SSA and suggests that issues of coordination driven by demand and supply constraints that negatively impact farmers may be addressed via policies for price stabilization (stable, predictable markets) and market support services. A study by Hartmann and colleagues [67] argues that if an increase in agricultural productivity is sought without a strategy for improving markets, it may lead to a collapse of prices and production. This was observed during the implementation of the International Fund for Agriculture Development's (IFAD) West African Root and Tubers Expansion Programs which experienced a negative impact on scaling-up due to a decline in output prices and reduced farmer income [67]. Attempting to increase yields (scale-up) without addressing market concerns may impact the production value chain.

\subsubsection{Technical and Physical Inputs}

Similar to our adoption results, we found that the farmers do not have access to technical and physical inputs, such as machinery, shelter, construction material, animal draft power, vaccination, and synthetic fertilizer to carry out the scaling-up process. Similarly, Sanchez [54] found a lack of options to access inputs, such as fertilizers, to be a major constraint that keeps SSA farmers at $1 \mathrm{t} / \mathrm{ha}$ yield, thus limiting the success of AgTs. Another study [68] also found that scaling-up of key crops, such as maize, rice, and groundnut can be achieved by the large-scale allocation of modern agricultural inputs such as fertilizer, improved seeds, credit facility, and easy access to the market. In a study by Msolla [69] also recommends establishing sustainable input supply systems in Tanzania and a report by Action 
Aid 2018 suggests the availability and quality of technical inputs to be a key constraint for scaling-up AgTs [70].

\subsubsection{Other Constraints}

The scaling-up assessment indicates various other constraints for scaling-up to be important. The farmers find that training, strengthening of networks, and social capital are necessary for AgTs to be widely accepted. Similarly, Muange and Nzula [62] discuss the crucial nature of social networks for the diffusion of information related to the adoption of AgTs in Tanzania. Financial means to adopt the AgTs is another constraint experienced by the farmers in our study region. Similarly, Mosley [71] argues that investments facilitating the effective adoption of AgTs are determined largely by farmers' income, access to credit, and the output/input price ratio. For example, some increase in fertilizer use is observed owing to subsidies and new lines of credit [54]. The farmers identify that the policy support for AgTs in the study area is neutral, and therefore limited, because it neither favors nor hampers the adoption of AgTs. In the case of the presence of a formalized program, the implementation is perceived as ineffective. Similarly, Mosley [71] argues that government policies and institutions influence access to basic assets, which in turn influence the uptake of an AgT.

\subsection{Overall Farmer Perceptions}

Overall, the final results (uptake potential of an AgT based on sustainability, adoption, and scaling-up assessment) are similar to the adoption results. As shown in Table 2 (Section 3.4.) both the use of fertilizers and improved seeds are perceived to have a good likelihood of successful uptake, whereas, small-scale irrigation is perceived to have an average likelihood of successful uptake.

Table 2. Results of sustainability, adoption, and scaling-up potential assessment as perceived by the farmers. ScalA = scaling-up assessment.

\begin{tabular}{cccc}
\hline ScalA Assessment & Use of Fertilizers & Improved Seeds & Small-Scale Irrigation \\
\hline $\begin{array}{c}\text { Sustainability } \\
\text { assessment }\end{array}$ & Sustainable & Sustainable & Sustainable \\
\hline Adoption assessment & Medium-low & Medium-high & Low \\
\hline Scaling-up assessment & High & High & Low \\
\hline Overall success potential & High & High & Medium \\
\hline
\end{tabular}

The final results provide evidence of the linkages between farmers' perceptions of sustainability, resources required for adoption, and scaling-up of AgTs. The farmers perceive sustainability, adoption, and scaling up of AgTs as processes that work in conjunction with each other and not as isolated processes with clear boundaries. Moreover, the perception of one impacts the other significantly, which makes a comprehensive integrated approach to study the uptake of AgTs a crucial consideration. In this sense, the study found (Table 2) that although small-scale irrigation is perceived by the farmers to be the most sustainable AgT of the three, it is also perceived to be the least adopted and least likely to scale-up successfully. This is due to the relatively higher number of adoption and scaling-up constraints anticipated by the farmers for small-scale irrigation. This suggests that although small-scale irrigation is highly desirable for sustainable development, the high initial constraints experienced by the farmers may lead to a low adoption rate, which in turn negatively impacts the scaling-up process. In contrast, although improved seeds, followed by the use of fertilizers, are perceived by the farmers to contribute to fewer sustainability factors, they are also perceived to be well adopted and most likely to scale-up successfully. This is due to the relatively lower number of adoption and scaling-up constraints anticipated by the farmers for both the use of fertilizers and improved seeds. This suggests that although the use of fertilizers and improved seeds contributes partially towards sustainability, they are still highly desirable for food security in the region. The low initial constraints experienced 
by the farmers may lead to a high adoption rate, which in turn positively impacts the scaling-up process. It also indicates initiatives of water stress tolerant high yielding seeds combined with fertilizer provision can increase yield levels in Tanzania or in SSA. The low adoption and scaling up of the AgTs can be traced to specific constraints experienced by the farmers that negatively influence the uptake process of an AgT. The farmers view the lack of marketing facilities and the high technical and physical inputs required to be the most significant constraint for both adoption and scaling-up of all three AgTs, followed by the lack of know-how skills and lack of added value of the AgTs.

The study finds that a farmer's willingness to take up an AgT is driven by his or her outlook regarding the sustainability, constraints for adoption, and constraints for scaling-up of the AgT. If the uptake process of an AgT is perceived to be relatively difficult by the farmer, meaning that, if the farmer thinks the AgT is not sustainable and that s/he may experience a number of constraints for adoption and scaling-up during the uptake process, then the farmer is less inclined to take up the AgT and vice versa. Given that farmers are the primary adopters and stakeholders in the agricultural process, it is important to understand the constraints for adoption of AgTs as observed and experienced by the farmer themselves to partially indicate the reasons for the low uptake of AgTs. More localized cases that shed light on household-level experiences are important to complement larger surveys as they can capture socially differentiated experiences and explore locally relevant factors significant for the success of AgTs.

\section{Conclusions}

The study found that farmers use a complex set of processes to understand and explain the uptake process of an AgT, and are effective at using the ScalA framework as a valuation tool. The results and valuation reflect that the integrated approach to assess the sustainability, adoption, and scaling-up of AgTs, systematically and simultaneously, is comprehensive and reflective of the complexities experienced by the farmers. A consideration of these three aspects from a farmer's perspective is crucial and useful for explaining the reasons (constraints) for limited adoption and scaling-up of AgTs.

Farmers' perceptions closely match the results of other empirical and policy studies in SSA and Tanzania, thus, providing a rationale for broader investigations stemming from representative data of farmer perceptions. For better and targeted agricultural management, the decision makers must emphasize the perceptions of the farmers and include them in the wider food security and development goals in Tanzania.

In contrast to many studies in SSA, the farmers perceive that the issue of low agricultural productivity and food insecurity are a result of limited adoption and scaling-up the AgTs, specifically, small-scale irrigation, rather than the issues of unsuitability (not sustainable) and irrelevance of AgTs for Tanzania. Given the current impediments on adoption and scaling-up of small scale irrigation, it may be viable strategy to introduce and promote drought tolerant high yielding varieties that are highly responsive to fertilizer inputs in the country or in SSA.

Interestingly, the farmers experience the lack of marketing facilities and technical and physical input as major constraints for both adoption and scaling-up. Agriculture and policy interventions must therefore first and foremost address the lack of technical and physical inputs the farmers anticipate, along with providing better marketing facilities. Other constraints indicate that agriculture and policy interventions may better promote knowledge dissemination regarding AgTs and emphasis more on the added value of AgTs for food and livelihood security.

Author Contributions: Conceptualization, S.J., H.K., M.L., T.S.A.-B., and S.S.; methodology, S.J., H.K., M.L., T.S.A.-B., and S.S.; software, S.J.; validation, S.J., H.K., and S.S.; formal analysis, S.J.; investigation, S.J., H.K., and M.L.; resources, S.S.; data curation, S.J.; writing-original draft preparation, S.J., M.L., and T.S.A.-B.; writing-review and editing, S.J., H.K., and S.S.; visualization, S.J., H.K., M.L., T.S.A.-B., and S.S.; supervision, H.K., M.L., and S.S.; project administration, S.S. All authors have read and agreed to the published version of the manuscript.

Funding: This research received no external funding. 
Acknowledgments: We are thankful to the SUSLAND team and the Leibniz Centre for Agricultural Landscape Research (ZALF) for their support and for providing necessary guidance concerning research and data. We are also grateful to the team at Sokoine University of Agriculture (SUA) for sharing their expertise and their technical support throughout implementation and data collection. We also express our sincere thanks to the researchers who devoted their time and effort to the implementation of the ScalA field trials.

Conflicts of Interest: The authors declare no conflicts of interest.

\section{Appendix A}

Table A1. Sustainability: Overview of all the factors of sustainability included in the analysis.

\begin{tabular}{cc}
\hline No. & Sustainability Factors \\
\hline 1 & AgTs lead to improvements in soil fertility \\
2 & AgTs contributes to erosion control \\
3 & AgTs have beneficial effects on water quality \\
4 & AgTs contribute to water supply \\
5 & AgTs improve biodiversity \\
6 & AgTs lead to improvements in income \\
7 & AgTs lead to improvements in food security \\
8 & AgTs lead to improved competitiveness of small-scale farmers \\
9 & AgTs increase resource use efficiency \\
10 & AgTs adapt to social norms \\
11 & AgTs lead to an adapted/adequate use of external inputs in order to decrease dependency \\
12 & AgTs integrate indigenous knowledge \\
13 & AgTs contribute to more equitable division of labor \\
14 & AgTs contribute to equitable access to services and education \\
15 & AgTs contribute to equal division of income and access to assets \\
16 & AgTs contribute to equitable access to rights \\
17 & AgTs improve the health status of local people and consumers \\
\hline
\end{tabular}

\section{Appendix B}

Table A2. Adoption: Overview of all the factors of adoption included in the analysis.

\begin{tabular}{cc}
\hline No. & Adoption Factors \\
\hline 1 & Laws (management, production, and processing) \\
2 & Processing facilities \\
3 & Infrastructure \\
4 & Social organizations and institutions \\
5 & Additional labor \\
6 & Organic inputs \\
7 & Additional land \\
8 & Financial capital (initial and maintenance) \\
9 & Marketing facilities \\
10 & Know-how skills \\
11 & Technical and physical inputs \\
\hline
\end{tabular}




\section{Appendix C}

Table A3. Scaling-up: Overview of all the factors of scaling-up included in the analysis.

\begin{tabular}{|c|c|}
\hline No. & Scaling-Up Factors \\
\hline 1 & Is the $\mathrm{AgT}$ affordable by farmers or can the target group carry the cost of the AgT? \\
\hline 2 & Is the knowledge, which is required for successful implementation available/is the AgT already known to the farmers? \\
\hline 3 & Is the AgT easy to understand and implement? \\
\hline 4 & Is the AgT initially adapted to labor endowment of farms? \\
\hline 5 & $\begin{array}{l}\text { Is the level of social organization, which is required for the implementation of the AgT available within the target community } \\
\text { (such as the formation of marketing networks, etc.)? }\end{array}$ \\
\hline 6 & $\begin{array}{c}\text { Are the organic inputs (such as crop residues, seeds, manure, bio pesticides, etc.) required for successful implementation of the } \\
\text { AgT initially available to farmers? }\end{array}$ \\
\hline 7 & $\begin{array}{c}\text { Are the technical inputs (such as vaccines, machinery, construction material, synthetic fertilizer, etc.) required by the AgT initially } \\
\text { available to farmers? }\end{array}$ \\
\hline 8 & $\begin{array}{c}\text { Can the AgT initially be implemented on existing farms and does not require additional land OR is the required additional land } \\
\text { available to the farmers? }\end{array}$ \\
\hline 9 & Are the benefits of the AgT easily observable by farmers? \\
\hline 10 & Can farmers quickly reap benefits from the AgT? \\
\hline 11 & Is the economic risk for farmers comparatively low? \\
\hline 12 & Is it possible for farmers to try out and verify the effects of the AgT by testing it on a small scale? \\
\hline 13 & $\begin{array}{l}\text { Is the implementation of the AgT flexible (i.e., can it be easily modified by other farmers to suit different ecologic and } \\
\text { socio-economic circumstances and needs within and outside the target area)? }\end{array}$ \\
\hline 14 & Does the AgT fit into the existing farming system and does it improve its efficiency? \\
\hline 15 & Does the AgT contribute to the farmer's autonomy, prestige, and independence? \\
\hline 16 & Does the AgT not increase pressure on natural resources such as water and land? \\
\hline 17 & Does the AgT offer potential for value adding in order to increase benefits? \\
\hline 18 & Does the organization have a well-designed overall concept (e.g., a binding rule system and a transparent structure)? \\
\hline 19 & Does the organization have a well-educated technical and management staff? \\
\hline 20 & Does the organization have a strong leadership with good reputation among the beneficiaries? \\
\hline 21 & Does the organization have access to an already existing structure of branch offices or other organizations based in the target area? \\
\hline 22 & Does the organization have experience with the target group? \\
\hline 23 & Does the organization have access to well-established networks to donors, policy-makers, researchers, and the private sector? \\
\hline 24 & Is staff trained to ensure participatory project selection and planning and in culturally sensitive approaches? \\
\hline 25 & Does the organization have access to basic assets such as power and to relevant communication systems? \\
\hline 26 & Is the objective of scaling-up clearly defined? \\
\hline 27 & $\begin{array}{c}\text { Does the organization have a clear strategy to reach the objective by defining the type, sequencing, and means employed for } \\
\text { scaling-up their activities? }\end{array}$ \\
\hline 28 & Does the organization have a well-established and effective documentation, monitoring, and evaluation system? \\
\hline 29 & Does the implementing agency use already existing information channels? \\
\hline 30 & Does the implementing agency use effective and efficient dissemination channels to promote/disseminate the AgT? \\
\hline 31 & Does the organization use efficient means to adequately spread information to each type of target audience? \\
\hline 32 & $\begin{array}{l}\text { Does the organization have a high-quality partnership with farmers (e.g., regular feedback mechanisms and exchange of } \\
\text { experience)? }\end{array}$ \\
\hline 33 & Is the organization engaged in capacity building and the implementation of sustainable supportive organizations at the local level? \\
\hline 34 & Does the implementing organization promote the AgT through mass media, such as radio, TV, or newspapers? \\
\hline 35 & Does the organization use only minimal incentives to introduce project activities? \\
\hline 36 & Is there political stability in the area/country? \\
\hline 37 & $\begin{array}{c}\text { Does the government promote supportive land, water, and agricultural policies, which facilitate the introduction/dissemination of } \\
\text { AgT activities among the target group/within the target area? }\end{array}$ \\
\hline 38 & Does the government support project activities/AgT through research and extension? \\
\hline 39 & Does the government have an efficient administration system that facilitates (or does not hinder) scaling-up activities? \\
\hline 40 & Is the governance system structured in an adequate, decentralized way? \\
\hline 41 & Is the situation of the civil society conducive to scaling-up of AgT activities at the local and regional/national level? \\
\hline 42 & Is there a functioning local level governance structure, which can act as a cooperation partner for scaling-up? \\
\hline 43 & $\begin{array}{c}\text { Are there already local organizations that can be used during the process of scaling-up to facilitate the dissemination of project } \\
\text { activities/AgTs? }\end{array}$ \\
\hline 44 & Are there local rules, which support or do not hamper scaling-up of project activities/AgT? \\
\hline 45 & Does the usage/access rights to land support or does not hamper the introduction of project activities/AgT? \\
\hline 46 & Does the spatial distribution of households not hamper project activities? \\
\hline 47 & Does a stable market exist to absorb the AgTs' produce? \\
\hline 48 & Are markets and marketing facilities easily accessible to farmers? \\
\hline 49 & Is the market price for the produce of the AgT predictable and attractive? \\
\hline 50 & Is there interest/support for the spread of the AgT by other economic actors? \\
\hline 51 & Is the necessary infrastructure such as access to roads, irrigation, electricity, and tap water available to the target group? \\
\hline 52 & Are processing facilities available to the target group? \\
\hline 53 & $\begin{array}{l}\text { Are there mechanisms that will enable farmers to eventually meet particular standards required by regional/national/international } \\
\text { markets? }\end{array}$ \\
\hline 54 & Are project activities/AgTs welcomed by the majority of the community? \\
\hline 55 & Are project activities/AgTs accepted by village leaders? \\
\hline 56 & Are project activities/AgTs welcomed by young farmers? \\
\hline 57 & Is the target group willing and able to actively participate and cooperate in project activities/the introduction of the AgT? \\
\hline 58 & Is individual engagement in AgT-related activities socially accepted? \\
\hline 59 & Is there entrepreneurial behavior within the community? \\
\hline
\end{tabular}




\section{References}

1. Otsuka, K.; Kijima, Y. Technology policies for a green revolution and agricultural transformation in Africa. J. Afr. Econ. 2010, 19, 60-76. [CrossRef]

2. Otsuka, K.; Muraoka, R. A Green Revolution for sub-Saharan Africa: Past failures and future prospects. J. Afr. Econ. 2017, 26, 73-98. [CrossRef]

3. Sarris, A.; Savastano, S.; Christiaensen, L. The Role of Agriculture in Reducing Poverty in Tanzania: A Household Perspective from Rural Kilimanjaro and Ruvuma. In Proceedings of the International Association of Agricultural Economists (IAAE) 2006 Annual Meeting, Queensland, Australia, 12-18 August 2006; International Association of Agricultural Economists: Queensland, Australia, 2006; pp. 1-36.

4. Greenberg, S.; Jones, G. Nuanced Rhetoric and the Path to Poverty: AGRA, Small-Scale Farmers, and Seed and Soil Fertility in Tanzania; The African Centre for Biosafety: Johannesburg, South Africa, 2015.

5. Mtaki, B. Tanzania-United Republic of Grain and Feed Annual 2019 Tanzania Corn, Wheat and Rice Report. Available online: https://apps.fas.usda.gov/newgainapi/api/report/downloadreportbyfilename? filename=GrainandFeedAnnual_DaresSalaam_Tanzania-UnitedRepublicof_4-9-2019.pdf (accessed on 11 October 2019).

6. Gitonga, K. Kenya Grain and Feed Annual Kenya Imports of Corn, Wheat, and Rice Expected to Surge. Available online: https://apps.fas.usda.gov/newgainapi/api/report/downloadreportbyfilename?filename= GrainandFeedAnnual_Nairobi_Kenya_3-18-2019.pdf (accessed on 11 October 2019).

7. Taylor, J. Ghana Grain and Feed Annual 2019 Annual Report. Available online: https: //apps.fas.usda.gov/newgainapi/api/report/downloadreportbyfilename?filename=GrainandFeedAnnual_ Accra_Ghana_4-11-2019.pdf (accessed on 11 October 2019).

8. Tran, Q. Vietnam Grain and Feed Annual 2019. Available online: https://apps.fas.usda.gov/newgainapi/api/ report/downloadreportbyfilename?filename=GrainandFeedAnnual_Hanoi_Vietnam_4-8-2019.pdf (accessed on 11 October 2019).

9. Kim, G. China-Peoples Republic of Grain and Feed Annual Grain Prices Reflect Political Risks—Outweighing Animal Disease Impacts. Available online: https:/apps.fas.usda.gov/newgainapi/api/report/ downloadreportbyfilename?filename=GrainandFeedAnnual_Beijing_China-PeoplesRepublicof_417-2019.pdf (accessed on 11 October 2019).

10. Mkonda, M.Y.; He, X. Yields of the major food crops: Implications to food security and policy in Tanzania's semi-arid agro-ecological zone. Sustainability 2017, 9, 1490. [CrossRef]

11. Pingali, P. Green Revolution:Impacts, Limits, and the path ahead. Proc. Natl. Acad. Sci. USA 2012, 109, 12302-12308. [CrossRef] [PubMed]

12. Teklewold, H.; Kassie, M.; Shiferaw, B. Adoption of multiple sustainable agricultural practices in rural Ethiopia. J. Agric. Econ. 2013, 64, 597-623. [CrossRef]

13. Kriesemer, S.K.; Virchow, D.; Weinberger, K.M. Assessing the sustainability of agricultural technology options for poor rural farmers. In Technological and Institutional Innovations for Marginalized Smallholders in Agricultural Development; Gatzweiler, F.W., von Braun, J., Eds.; Springer International Publishing: Bonn, Germany, 2016; pp. 199-211. ISBN 9783319257181.

14. Glover, D.; Sumberg, J.; Andersson, J.A. The adoption problem; or why we still understand so little about technological change in African agriculture. Outlook Agric. 2016, 45, 3-6. [CrossRef]

15. Westermann, O.; Förch, W.; Thornton, P.; Körner, J.; Cramer, L.; Campbell, B. Scaling up agricultural interventions: Case studies of climate-smart agriculture. Agric. Syst. 2018, 165, 283-293. [CrossRef]

16. Rotmans, J. Scaling in Integrated Assessment: Problem or Challenge? Integr. Assess. 2002, 3, $266-279$. [CrossRef]

17. Wu, J.; Jones, K.B.; Li, H.; Loucks, O.L. Scaling With Unknown Uncertainty: A Synthesis. In Scaling and Uncertainty Analysis in Ecology: Methods and Applications; Springer: Dordrect, The Netherlands, 2006; pp. 329-346. ISBN 1402046642.

18. Evenson, R.E.; Gollin, D. Assessing the impact of the green revolution, 1960 to 2000. Science 2003, 300, 758-762. [CrossRef]

19. Enyong, L.A.; Debrah, S.K.; Bationo, A. Farmers' perceptions and attitudes towards introduced soil-fertility enhancing technologies in western Africa. Nutr. Cycl. Agroecosystems 1999, 53, 177-187. [CrossRef] 
20. Kilima, F.; Tarimo, A.; Johnsen, F.; Nchimbi-Msolla, S.; Mbaga, S.; Sesabo, J.; Abdallah, J.; Iranga, G. The Impact of Agricultural Research on Poverty and Income Distribution: A Case Study of Selected On-farm Research Projects at Sokoine University of Agriculture, Morogoro, Tanzania. Tanzania J. Agric. Sci. 2013, 12, $1-9$.

21. Negatu, W.; Parikh, A. The impact of perception and other factors on the adoption of agricultural technology in the Moret and Jiru Woreda (district) of Ethiopia. Agric. Econ. 1999, 21, 205-216. [CrossRef]

22. Sinjaa, J.; Karugia, J.T.; Baltenweck, I.; Waithaka, M.M.; Miano, M.D.; Nyikal, R.A.; Romney, D. Farmer perception of technology and its impact on technology uptake: The case of fodder legumes in Central Kenya Highlands. In Proceedings of the African Association of Agricultural Economists. Shaping the Future of African Agriculture for Development: The Role of Social Scientists. Proceedings of the Inaugural Symposium, Grand Regency Hotel, Nairobi, Kenya, 6-8 December 2004; African Association of Agricultural Economists (AAAE): Nairobi, Kenya, 2004; pp. 1-11.

23. Mwangi, M.; Kariuki, S. Factors Determining Adoption of New Agricultural Technology by Smallholder Farmers in Developing Countries. J. Econ. Sustain. Dev. 2015, 6, 208-216.

24. Sieber, S.; Jha, S.; Tharayil Shereef, A.-B.; Bringe, F.; Crewett, W.; Uckert, G.; Polreich, S.; Ndah, T.H.; Graef, F.; Mueller, K. Integrated assessment of sustainable agricultural practices to enhance climate resilience in Morogoro, Tanzania. Reg. Environ. Chang. 2015, 15, 1281-1292. [CrossRef]

25. Versteeg, M.N.; Amadji, F.; Eteka, A.; Gogan, A.; Koudokpon, V. Farmers' adoptability of Mucuna fallowing and agroforestry technologies in the coastal savanna of Benin. Agric. Syst. 1998, 56, 269-287. [CrossRef]

26. Douthwaite, B.; Keatinge, J.D.H.; Park, J.R. Why promising technologies fail: The neglected role of user innovation during adoption. Res. Policy 2001, 30, 819-836. [CrossRef]

27. Mcrobert, J.; Rickards, L. Social research: Insights into farmers' conversion to no-till farming systems. Ext. Farming Syst. J. 2010, 6, 43-52.

28. Adesina, A.A.; Baidu-Forson, J. Farmers' perceptions and adoption of new agricultural technology: Evidence from analysis in Burkina Faso and Guinea, West Africa. Agric. Econ. 1995, 13, 1-9. [CrossRef]

29. Dessart, F.J.; Barreiro-Hurlé, J.; Van Bavel, R. Behavioural factors affecting the adoption of sustainable farming practices: A policy-oriented review. Eur. Rev. Agric. Econ. 2019, 46, 417-471. [CrossRef]

30. Feder, G.; Just, R.E.; Zilberman, D. Adoption of agricultural innovations in developing countries: A survey. Econ. Dev. Cult. Chang. 1985, 33, 255-298. [CrossRef]

31. Foster, A.D.; Rosenzweig, M.R. Microeconomics of Technology Adoption. Annu. Rev. Econom. 2010, 2, 395-424. [CrossRef] [PubMed]

32. Lee, D. Agricultural sustainability and technology adoption: Issues and policies for developing countries. Am. J. Agric. Econ. 2005, 87, 1325-1334. [CrossRef]

33. SUSLAND Trans-SEC-Innovating Strategies to safeguard Food Security using Technology and Knowledge Transfer: A people-centred Approach. Available online: http://www.trans-sec.org/ (accessed on 29 April 2019).

34. Barron, J.; Rockström, J.; Gichuki, F.; Hatibu, N. Dry spell analysis and maize yields for two semi-arid locations in east Africa. Agric. For. Meteorol. 2003, 117, 23-37. [CrossRef]

35. Jha, S.; Kaechele, H.; Sieber, S. Factors Influencing the Adoption of Water Conservation Technologies by Smallholder Farmer Households in Tanzania. Water 2019, 11, 2640. [CrossRef]

36. Msanya, B.M.; Kimaro, D.N.; Kimbi, G.G.; Kileo, E.P.; Mbogoni, J.J.D.J. Land Resources Inventory and Suitability Assessment for the Production of the Major Crops inthe Eastern Part of Morogoro Rural District, Tanzania; Soils and Land Resources of Morogoro Rural and Urban Districts: Morogoro, Tanzania, 2001.

37. Mulvaney, R.L.; Khan, S.A.; Ellsworth, T.R. Synthetic Nitrogen Fertilizers Deplete Soil Nitrogen: A Global Dilemma for Sustainable Cereal Production. J. Environ. Qual. 2009, 38, 2295-2314. [CrossRef]

38. Michelson, H.C.; Fairbairn, A.; Maertens, A.; Ellison, B.; Manyong, V.M. Misperceived Quality: Fertilizer in Tanzania. SSRN Electron. J. 2018, 1-48. [CrossRef]

39. Monela, A.G. Access to and Adoption of Improved Seeds by Smallholder Farmers in Tanzania; Sokoine University Of Agriculture: Morogoro, Tanzania, 2014.

40. Passarelli, S.; Mekonnen, D.; Bryan, E.; Ringler, C. Evaluating the pathways from small-scale irrigation to dietary diversity: Evidence from Ethiopia and Tanzania. Food Secur. 2018, 10, 981-997. [CrossRef]

41. Singh, R.K.; Murty, H.R.; Gupta, S.K.; Dikshit, A.K. An overview of sustainability assessment methodologies. Ecol. Indic. 2009, 9, 189-212. [CrossRef] 
42. Rigby, D.; Woodhouse, P.; Young, T.; Burton, M. Constructing a farm level indicator of sustainable agricultural practice. Ecol. Econ. 2001, 39, 463-478. [CrossRef]

43. Rogers, E.M. Diffusion of Innovations, 5th ed.; Simon and Schuster: New York, NY, USA, 2003; ISBN 9780743222099.

44. Sunding, D.; Zilberman, D. The agricultural innovation process: Research and technology adoption in a changing agricultural sector. In Handbook of Agricultural Economics; Elsevier: Amsterdam, The Netherlands, 2001; pp. 207-261.

45. Binswanger, H.P.; Aiyar, S.S. Scaling Up Community-Driven Development: Theoretical Underpinnings and Program Design Implications; The World Bank: Washington, DC, USA, 2003.

46. Uvin, P. Fighting hunger at the grassroots: Paths to scaling up. World Dev. 1995, 23, 927-939. [CrossRef]

47. Crewett, W.; Bringe, F.; Sieber, S. Scaling Up of Good Agricultural Practices. The Operational Assessment Tool (ScalA Tool Handbook); Research, L.-C., Ed.; Leibniz-Center for Agricultural Landscape Research, Gesellschaft für Technische Zusammenarbeit (GTZ): Müncheberg, Germany, 2006.

48. Voortman, R.L. Why the Green Revolution failed in sub-Saharan Africa. Rural 21 Int. J. Rural Dev. 2013, 47, 32-33.

49. De Fraiture, C.; Giordano, M. Small private irrigation: A thriving but overlooked sector. Agric. Water Manag. 2014, 131, 167-174. [CrossRef]

50. Domènech, L. Improving irrigation access to combat food insecurity and undernutrition: A review. Glob. Food Sec. 2015, 6, 24-33. [CrossRef]

51. Harrison, E.; Mdee, A. Successful small-scale irrigation or environmental destruction? The political ecology of competing claims on water in the Uluguru Mountains, Tanzania. J. Polit. Ecol. 2017, 24, 406. [CrossRef]

52. Kijima, Y.; Otsuka, K.; Sserunkuuma, D. An inquiry into constraints on a green revolution in sub-Saharan Africa: The case of NERICA Rice in Uganda. World Dev. 2011, 39, 77-86. [CrossRef]

53. Amjath-Babu, T.S.; Krupnik, T.J.; Kaechele, H.; Aravindakshan, S.; Sietz, D. Transitioning to groundwater irrigated intensified agriculture in Sub-Saharan Africa: An indicator based assessment. Agric. Water Manag. 2016, 169, 125-135. [CrossRef]

54. Sanchez, P.A. En route to plentiful food production in Africa. Nat. Plants 2015, 1, 4014. [CrossRef]

55. Mugisha, J.; Diiro, G. Explaining the Adoption of Improved Maize Varieties and its Effects on Yields among Smallholder Maize Farmers in Eastern and Central Uganda. Middle-East J. Sci. Res. 2010, 5, 6-13.

56. Simtowe, F.; Kassie, M.; Diagne, A.; Asfaw, S.; Shiferaw, B.; Silim, S.; Muange, E. Determinants of agricultural technology adoption: The case of improved pigeonpea varieties in tanzania. Q. J. Int. Agric. 2011, 50, 325-345.

57. Sakaki, M.; Koga, K. An effective approach to sustainable small-scale irrigation developments in Sub-Saharan Africa. Paddy Water Environ. 2013, 11, 1-14. [CrossRef]

58. Fujiie, H.; Maruyama, A.; Fujiie, M.; Takagaki, M.; Merrey, D.J.; Kikuchi, M. Why invest in minor projects in sub-Saharan Africa? An exploration of the scale economy and diseconomy of irrigation projects. Irrig. Drain. Syst. 2011, 25, 39-60. [CrossRef]

59. Kadigi, R.M.J. Use of Participatory Farmer Groups Model to Transfer Agricultural Technology: Is it making any difference in the Tanzanian agriculture? J. Renew. Agric. 2013, 1, 113. [CrossRef]

60. Suri, T. Selection and Comparative Advantage in Technology Adoption. Econometrica 2011, 79, 159-209.

61. Matsumoto, T.; Yamano, T.; Sserunkuuma, D. Technology adoption in agriculture: Evidence from experimental intervention in maize production in Uganda. In An African Green Revolution: Finding Ways to Boost Productivity on Small Farms; Springer: Dordrecht, The Netherlands, 2013; pp. 261-278. ISBN 9789400757608.

62. Muange, E.N.; Nzula, E. Social Networks, Technology Adoption and Technical Efficiency in Smallholder Agriculture: The Case of Cereal Growers in Central Tanzania; Faculty of Agricultural Sciences, Georg-August University of Gottingen: Göttingen, Germany, 2014.

63. Kahimba, F.C.; Mutabazi, K.D.; Tumbo, S.D.; Masuki, K.F.; Mbungu, W.B. Adoption and Scaling-Up of Conservation Agriculture in Tanzania: Case of Arusha and Dodoma Regions. Nat. Resour. 2014, 5, 161-176. [CrossRef]

64. Mustapha, A. Amina Effectiveness of Extension Methods for Scaling Up Improved Common Bean Technologies among Small-Scale Farmers in Babati District, Tanzania; Sokoine University Of Agriculture: Morogoro, Tanzania, 2017.

65. Pingali, P.L.; Bigot, Y.; Binswanger, H.P. Agricultural mechanization and the evolution of farming systems in sub-Saharan Africa. Econ. Geogr. 1988, 64, 391. 
66. Poulton, C.; Kydd, J.; Dorward, A. Overcoming market constraints on pro-poor agricultural growth in sub-Saharan Africa. Dev. Policy Rev. 2006, 24, 243-277. [CrossRef]

67. Hartmann, A.; Kharas, H.; Kohl, R.; Linn, J.; Massler, B.; Sourang, C. Scaling up programs for the rural poor: IFAD's experience, lessons and prospects (phase 2). Available online: https://www.ifad.org/en/web/ knowledge/publication/asset/40279951 (accessed on 19 December 2019).

68. Kidane, A.; Hepelwa, A.; Tingum, E.; Hu, T.W. Agricultural Inputs and Efficiency in Tanzania Small Scale Agriculture: A Comparative Analysis of Tobacco and Selected Food Crops. Tanzanian Econ. Rev. 2013, 1, 1-13.

69. Msolla, M.M. Increasing Investment in the Fertilizer Value Chain-The AFAP Model in Tanzania. Available online: https://www.ipipotash.org/uploads/udocs/5-increasing-investment-in-the-fertilizer-value-chainmsolla.pdf (accessed on 11 October 2019).

70. Wijeratna, A. Agroecology: Scaling-Up, Scaling-Out. Available online: https://actionaid.org/sites/default/ files/agroecology_def_web.pdf (accessed on 11 October 2019).

71. Mosley, P. Policy and capital market constraints to the African Green Revolution: A study of maize and sorghum yields in Kenya, Malawi and Zimbabwe, 1960-1991. In From Adjustment to Development in Africa; Palgrave Macmillan: London, UK, 1994; pp. 248-272. ISBN 978-1-349-23596-4.

(C) 2020 by the authors. Licensee MDPI, Basel, Switzerland. This article is an open access article distributed under the terms and conditions of the Creative Commons Attribution (CC BY) license (http://creativecommons.org/licenses/by/4.0/). 